\title{
Identifying Best Practices for Long-Term Success in Supported Employment
}

\author{
Danielle Russell ${ }^{1}$ a \\ 1 Wisconsin Division of Vocational Rehabilitation \\ Keywords: supported employment, vocational rehabilitation \\ https://doi.org/10.52017/001c.29111
}

\section{Rehabilitation Counselors and Educators Journal}

Vol. 10, Issue 2, 2021

\begin{abstract}
Supported employment (SE) and customized employment are key services designed to assist individuals with significant cognitive and psychosocial disabilities successfully obtain and maintain employment. The Wisconsin Division of Vocational Rehabilitation (DVR) sought to better understand whether individuals receiving SE through the public VR program returned for further employment assistance following successful case closure. Patterns in service delivery between non-return and return consumers were identified and can be used to inform best practices in serving these populations. Several types of services (e.g., On-the-Job Training) were determined as significantly associated with one's return to VR, indicating that consumers with significant disabilities may return for further services following successful case closure. DVR counselors should be aware that consumers achieving successful supported employment outcomes may need additional or continuous disability-specific or job-related training and support.
\end{abstract}

\section{Background and Purpose}

Research consistently underscores the efficacy of supported employment (SE) services in improving vocational outcomes for individuals with significant mental impairments (Bond et al., 2008; Bond \& Drake, 2014; Campbell et al., 2011). Within the public vocational rehabilitation (VR) program, mental impairments are coded as cognitive (e.g., impairments involving learning, thinking, processing information, and concentration), psychosocial (e.g., interpersonal and behavioral impairments, difficulty coping), or other (Rehabilitation Services Administration, 2017; Schalock et al., 2021). The Workforce Innovation and Opportunity Act (WIOA) of 2014 further clarified the definition of SE as integrated, competitive employment within the community, typically driven by labor market needs, with training and support provided by a skilled job coach (Smith et al., 2015, 2017).

As a result of WIOA implementation, the state VR agencies, including the Wisconsin Division of Vocational Rehabilitation (DVR), prepared for a possible increase in the number of supported employment cases. VR counselors at DVR anecdotally reported that supported employment consumers were returning to receive further or additional services after successful case closure. This study was designed to explore if case data substantiated the anecdotal reports regarding the return to DVR of those previously closed successfully in supported employment. Specifically, the purpose of this study was to identify trends in service delivery between non-return cases and return cases to evaluate the effectiveness of DVR's supported employment service delivery, and the best practices for long-term consumer success in supported employment. The following evaluation questions were posed:

1. Are significant numbers of supported employment consumers returning to DVR after successful case closure?

2. Were there identifiable patterns in service delivery between non-return and return consumers that indicate best practices for retention?

\section{Methods}

A quantitative analysis of existing state VR program data was used for this study. The target population was consumers who had a supported employment plan type and exited DVR from 01/01/2014 to 6/30/2017. Consumer data was first extracted from the DVR's case management system (IRIS) and merged with the RSA-911 data. Using the merged dataset, a series of t-tests were performed with IBM SPSS, including one's return status as the dependent variable to determine if specific services were correlated to retention.

\section{Results}

There were 741 consumers with a supported employment plan type whose vocational rehabilitation cases were closed as successfully rehabilitated from $01 / 01 / 2014$ to $06 / 30 / 2017$. 
Table 1. Supported Employment Case Averages: Days From Employment to Exit, Hours Worked, and Hourly Wage

\begin{tabular}{|c|c|c|c|}
\hline & Non-return & Return & All SE cases \\
\hline Average days from employment to case closure* & 252.18 & 207.63 & 240.64 \\
\hline Average hours worked per week & 16.13 & 15.48 & 15.96 \\
\hline Average hourly wage* & $\$ 8.62$ & $\$ 8.33$ & $\$ 8.54$ \\
\hline
\end{tabular}

$* \mathrm{p}$-value $<.05$

Table 2. Services Provided to Supported Employment Consumers With Cognitive Impairments

\begin{tabular}{|c|c|c|c|}
\hline & Non-return & Return & All SE cases \\
\hline Job Readiness Training* & $138(31.36 \%)$ & 55 (34.81\%) & $193(32.27 \%)$ \\
\hline Job Search Assistance & 384 (87.27\%) & $137(86.71 \%)$ & $521(87.12 \%)$ \\
\hline
\end{tabular}

* p-value $<.05$

Of those 741 consumers, 192 returned to DVR for further services prior to $01 / 01 / 2020$, and 549 did not return prior to that date. In other words, $25.91 \%$ of supported employment consumers returned to vocational rehabilitation after a successful closure. While this finding may not appear high, further exploration into the service patterns of those who returned, compared with those who did not, was conducted to understand how the VR program can better serve this population.

\section{Length of Time \& Quality of Employment}

Across all supported employment case closures, the average days between employment and successful case closure differed significantly between those who returned (207.63 days) and those who did not return (252.18 days). Those who returned to DVR had their cases closed an average of 44.55 days earlier than those who did not return for services (see Table 1). Of the employment characteristics data, a two-tailed t-test in SPSS showed that only hourly wage was found to be significantly related to outcome, with a pvalue of .021. There were no significant differences between the two groups in terms of hours worked per week or occupation (i.e., O*NET code). Expense (i.e., the amount DVR spent during the case) was not found to be significantly related to outcome.

\section{Patterns of Services Received}

\section{Consumers With Cognitive Impairments}

Of the 598 consumers with primary or secondary cognitive impairments, 158 (26.42\%) returned to DVR for further services prior to $01 / 01 / 2020$. Of the demographic data in this model, a two-tailed t-test in SPSS showed that only age was found to be significantly related to outcome, with a p-value of .043. There were no significant differences in ethnicity, race, and gender between the two groups (return and non-return consumers). One service was found to be significantly related to outcome, with a p-value of .048: Job Readiness Training. A second service, Job Search Assis- tance, was found to be borderline significantly related to outcome, with a p-value of .068. See Table 2.

\section{Consumers With Psychosocial Impairments}

Of the 328 consumers with primary or secondary psychosocial impairments, 94 (28.66\%) returned to DVR for further services prior to $01 / 01 / 2020$. According to a twotailed t-test in SPSS, there were no significant differences in age, ethnicity, race, or gender between the two groups (return and non-return consumers). Four services were found to be significantly related to one's return status: Assessment ( $\mathrm{p}=.039)$; On-the-Job Training ( $\mathrm{p}=.013)$; DisabilityRelated Skills Training $(\mathrm{p}=.014)$; and Information and Referral Services $(p=.001)$. Two services were found to be borderline significantly related to outcome: Rehabilitation Technology $(p=.061)$ and Job Search Assistance $(p=.067)$. See Table 3 .

\section{Recommendations and Implications for Practice}

Over a five-year period, the rate at which supported employment consumers returned to vocational rehabilitation after a successful closure was $25.91 \%$. A series of t-tests and descriptive analyses found several factors related to one's return status to VR. At first, an hourly wage was significantly linked to one's return to VR. As the recent legislation intends to direct VR consumers away from the subminimum wage work and into competitive integrated employment, VR counselors and agency partners are working to assist consumers with finding employment at competitive wages.

Several types of services (e.g., On-the-Job Training) were also determined as significantly associated with one's return to VR, indicating that consumers with significant disabilities may return for further services following successful case closure. DVR counselors should be aware that consumers achieving successful supported employment may need additional or continuous disability-specific or job-related training.

Another factor to consider is customized employment 
Table 3. Services Provided to Supported Employment Consumers With Psychosocial Impairments

\begin{tabular}{lccc}
\hline & Non-return & Return & All SE cases \\
\hline Assessment* $^{*}$ & $163(69.66 \%)$ & $78(82.98 \%)$ & $241(73.48 \%)$ \\
On-the-Job Training* $^{*}$ & $12(5.13 \%)$ & $12(12.77 \%)$ & $24(7.32 \%)$ \\
Job Search Assistance* & $174(74.36 \%)$ & $49(52.13 \%)$ & $223(67.99 \%)$ \\
Information and Referral Services* & $108(46.15 \%)$ & $61(64.89 \%)$ & $169(51.52 \%)$ \\
\hline
\end{tabular}

$* \mathrm{p}$-value $<.05$

(CE) services, which are related to supported employment (SE) services and defined by WIOA. Of the 741 individuals in the sample, only four received CE services. This indicates that CE is a seriously underutilized service at DVR, particularly for those eligible for SE services. Contemporary research suggests that to effectively implement CE practices, relevant stakeholders, including vocational rehabilitation counselors, must receive training on both process and philosophy, and be invited to engage in the process (Smith et al., 2017).

DVR can use the baseline information and lessons learned through this study to identify areas of training needs for DVR staff and to inform further qualitative study on supported and customized employment, such as a focus group that includes community partners and VR counselors. More research is needed to understand the relationship between the outcomes of consumers with psychosocial impairments who returned to DVR after successful closure and the rate of services they received when compared with those who do not return. Findings suggest that a better understanding of how to serve consumers with psychosocial impairments presents an opportunity to improve longerterm employment outcomes with this population. The following recommendations are shared to help inform future evaluation efforts:

- Program evaluation can raise as many questions as it answers. If planning a mixed method or multi-stage study, allow space to adapt subsequent stages to incorporate additional questions revealed during the earlier stages.

- Ask data experts in the agency about potential limitations to ensure the right data are being used for the evaluation and to avoid misinterpreting the results.

- Engage stakeholders early in the evaluation development process to increase the likelihood the evaluation results will be used.

- DVR may be closing cases too early; it is important to ensure stability on the job before case closure.

- VR staff may benefit from additional training in working with individuals with psychosocial impairments to improve capacity to effectively serve this population through supported and customized employment services.

\section{Author Note}

The contents of this paper were developed under a cooperative agreement with the U.S. Department of Education, Technical Assistance Center for Vocational Rehabilitation Agency Program Evaluation and Quality Assurance (PEQA-TAC) (Grant Award Number: H263B150004). However, the contents and views expressed in this publication do not necessarily represent the positions or policies of the U.S. Department of Education, and you should not assume endorsement by the Federal government. 


\section{References}

Bond, G. R., \& Drake, R. E. (2014). Making the case for IPS supported employment. Administration and Policy in Mental Health, 41(1), 69-73. https://doi.org/10.100 7/s10488-012-0444-6

Bond, G. R., Drake, R. E., \& Becker, D. R. (2008). An update on randomized controlled trials of evidencebased supported employment. Psychiatric Rehabilitation Journal, 31(4), 280-290. https://doi.org/ 10.2975/31.4.2008.280.290

Campbell, K., Bond, G. R., \& Drake, R. E. (2011). Who benefits from supported employment: A metaanalytic study. Schizophrenia Bulletin, 37(2), 370-380. https://doi.org/10.1093/schbul/sbp066

Rehabilitation Services Administration. (2017). Revision of Policy Directive (PD) 16-04 instructions for the completion of the Case Service Report Manual (RSA-911) for the State Vocational Rehabilitation Services Program and the State Supported Employment Services Program. https://rsa.ed.gov/sites/default/file s/subregulatory/pd-16-04.pdf
Schalock, R. L., Luckasson, R., \& Tasse, M. J. (2021). Intellectual disability: Definition, classification, and systems of supports. American Association on Intellectual and Developmental Disabilities.

Smith, T. J., Dillahunt-Aspillaga, C. J., \& Kenney, C. (2015). Integrating customized employment practices within the vocational rehabilitation system [Special edition]. Journal of Vocational Rehabilitation, 42(3), 201-208. https://doi.org/10.3233/JVR-150740

Smith, T. J., Dillahunt-Aspillaga, C. J., \& Kenney, R. M. (2017). Implementation of customized employment provisions of the Workforce Innovation and Opportunity Act within vocational rehabilitation systems. Journal of Disability Policy Studies, 27(4), 195-202. https://doi.org/10.1177/1044207316644412 